\title{
Saúde suplementar no Distrito Federal: o que pensa o Tribunal de Justiça do Distrito Federal e Territórios.
}

\section{Supplementary health at the Federal District: what thinks the Federal District and Territories Justice Court.}

\section{Salud suplementaria en el Distrito Federal: lo que piensa el Tribunal de Justicia del Distrito Federal y Territorios.}

Sandra Mara CAMPOS ALVES ${ }^{1}$

Maria Célia DELDUQUE ${ }^{2}$

Armando RAGGIO ${ }^{3}$

RESUMO: A pesquisa procurou avaliar o entendimento do Poder Judiciário no enfrentamento de demandas envolvendo a assistência à saúde suplementar, através da análise de decisões judiciais do Tribunal de Justiça do Distrito Federal e Territórios - TJDFT. A pesquisa coletou e analisou as decisões judiciais de $2^{\mathrm{a}}$ instância proferidas pelo Tribunal de Justiça do Distrito Federal e Territórios, publicadas no período de 2009 a 2011. Observou-se que a regulamentação expedida pela ANS não encontra eco nas decisões judiciais, sendo as decisões fundamentadas prioritariamente com base no Código de Defesa do Consumidor, Código de Processo Civil, e outros textos legais. Concluiu-se que o Poder Judiciário vem se mostrando atento à defesa do direito à saúde, na dimensão da saúde suplementar.

PALAVRAS-CHAVE: Poder Judiciário; Saúde suplementar; Direito Sanitário

\footnotetext{
ABSTRACT: The survey sought to assess the understanding of the Judiciary confrontation of demands involving supplementary healthcare, through the analysis of judgments of the Federal District and Territories Justice Court - TJDFT. The survey collected and analyzed the judgments of appeal handed down by the Court, published from 2009 to 2011. It was observed that the regulation issued by ANS finds no echo in judicial decisions being decisions based primarily based the

1 Advogada, Especialista em Direito Sanitário pela Fiocruz Brasília, Mestre em Política Social e doutoranda em Saúde Coletiva pela Universidade de Brasília, pesquisadora colaboradora do Programa de Direito Sanitário da Fiocruz Brasília.

2 Advogada, Doutorado em Saúde Pública pela USP e Pós-doutorado em Direito pela Universidad de Cantabria. Coordenadora do Programa de Direito Sanitário da Fiocruz.-Brasília.

3 Mestrado em Bioética pela UnB, doutorado por notório saber pela Fundação Oswaldo Cruz.
} 
Consumer Defense Code, the Code of Civil Procedure, and other legal texts. It was concluded that the Judiciary has been showing attention to the defense of the right to health, on the supplementary health dimension.

KEYWORDS: Judiciary; Supplemental Health; Health law

RESUMEN: El estudio pretendía evaluar la comprensión del poder judicial en el enfrentamiento de las exigencias de salud suplementaria, a través del análisis de las sentencias de la Corte de Justicia del Distrito Federal y Territorios - TJDFT. La encuesta recogió y analizó las sentencias de apelación del Tribunal publicadas en el período entre 2009 y 2011. Se observó que el Reglamento de la ANS no encuentra ningún eco en las decisiones judiciales, siendo las decisiones basadas sobre el Código de Defensa del Consumidor, del Código de Procedimiento Civil y otros textos jurídicos. Se concluyó que el poder judicial mostró atención a la defensa del derecho a la salud, en la dimensión de la salud suplementaria.

PALABRAS CLABE: Poder Judicial; Salud Complementaria; Derecho Sanitário

\section{INTRODUÇÃO}

O direito à saúde é reconhecido pela Constituição Brasileira de 1988 como um direito social de todos, devendo ser empreendido esforços do Estado, através de políticas sociais e econômicas, no sentido de garanti-lo. Em que o pese o Brasil ter optado pela criação de um sistema público e universal de saúde - Sistema Único de Saúde (SUS) - essa mesma Carta Política permitiu que a assistência à saúde fosse atividade livre à iniciativa privada.

Conformou-se assim, no plano da assistência à saúde, a convivência de dois modelos de saúde, o modelo público e o privado. O modelo privado, que funciona de forma suplementar ao modelo público e universal, é composto ainda por dois subsistemas, em que no primeiro se observa a comercialização de planos e seguros de saúde (saúde suplementar) e no outro, o exercício privado das atividades médicas.

A assistência à saúde como uma atividade livre à iniciativa privada foi responsável pela criação de um grande mercado no Brasil, o da comercialização de planos e seguros de saúde que em números atuais conta com 48.660 .705 de beneficiários em planos privados de assistência médica com ou sem odontologia, e 18.440.037 de beneficiários de planos privados exclusivamente odontológicos. ${ }^{1}$ O Distrito Federal ocupa o $4^{\circ}$ lugar entre as unidades da federação com maior proporção de população coberta por planos e seguros saúde versus população. ${ }^{1}$

Concomitantemente a esse aumento da comercialização, cresceu também o número de ações judiciais que têm como objeto a saúde suplementar. Diante desse panorama foi realizado estudo com o objetivo de analisar os acórdãos do Tribunal de Justiça do Distrito Federal e Territórios que 
versavam sobre demandas judiciais envolvendo a saúde suplementar e identificar o posicionamento desse órgão no enfretamento do tema.

\section{A evolução da assistência privada à saúde no Brasil e seu processo de regulamentação}

A assistência privada à saúde, em suas diversas modalidades, não é atividade recente. Registros demonstram que o "primeiro ciclo de expansão do empresariamento dos serviços de saúde no país é impulsionado pela Previdência Social.".

Assim, nos anos de 1930, os Institutos de Aposentadorias e Pensões (IAPs), organizados por categorias profissionais, concediam aos seus associados - trabalhadores urbanos formais benefícios previdenciários e de assistências médica, sendo esses últimos realizados principalmente por prestadores privados que eram contratados para a realização desses serviços de saúde.

Posteriormente, na década de 1940, surgiram os primeiros planos próprios de autogestão Caixa de Assistência aos Funcionários do Banco do Brasil (CASSI) e o Instituto de Aposentadoria e Pensões dos Industriários. ${ }^{3}$

A partir dos anos de 1950, com o forte processo de urbanização e industrialização no Brasil, surgiu "uma demanda por sistemas de proteção mais estruturados aos trabalhadores, incorporando práticas consolidadas nos países de origem das empresas multinacionais recém-instaladas"3. O governo brasileiro passou então a estimular que as próprias empresas privadas assumissem a responsabilidade pela saúde de seus trabalhadores.

O Decreto-Lei $\mathrm{n}^{\mathrm{o}} 73$, de 1966, que dispunha sobre o sistema nacional de seguros privados no Brasil foi o responsável então pela regulamentação do convênio-empresa, sendo considerado o primeiro marco regulatório sobre o tema. O convênio-empresa, inicialmente financiado pela Previdência Social, consistia no pagamento direto feito às empresas que optavam em atender seus empregados através de empresas médicas, de medicina de grupo, ou ainda que estruturassem uma rede de atendimento, administrado pela própria empresa. Posteriormente essa contratação passou a ser realizada diretamente entre o empregador e as empresas de medicina ${ }^{4}$.

Essa estratégia adotada pelo Estado serviu para impulsionar ainda mais o mercado privado da saúde de modo que no mesmo ano da publicação do Decreto Lei $\mathrm{n}^{\circ} 73$ foi fundada a Associação Brasileira de Medicina de Grupo (Abramge), e no ano seguinte as Cooperativas Médicas. "Dez anos depois, em 1977, havia quase 5 mil convênios-empresa, que cobria cerca de $10 \%$ da população previdenciária". 3

O Decreto-Lei nº 73, de 1966 previu ainda a criação da Superintendência de Seguros Privados 
- SUSEP, entidade responsável pela fiscalização da constituição, organização, funcionamento e operações das Sociedades Seguradoras, incluídas aqui as empresas que operavam os seguros-saúde.

Apenas no período compreendido entre o final dos anos de 1980 e o início dos anos de 1990, a área de saúde suplementar no Brasil teve a sua segunda grande expansão. Alguns dos fatores que influenciaram esse crescimento foi o comprometimento do orçamento público para a saúde, com a consequente escassez e baixa qualidade dos serviços ofertados; a incorporação tecnológica com a presença de novos procedimentos médicos e de diagnósticos; a ampliação de oferta de planos privados coletivos, para o funcionalismo público e para o setor privado, entre outros. ${ }^{5}$

A ampliação do número de planos privados de saúde, a convalidação do sistema misto de assistência à saúde pela nova Carta Magna promulgada em 1988 e a fraca atividade reguladora por parte do Estado trouxeram consigo uma série de questões.

A situação do mercado de planos e seguros de saúde se caracterizava principalmente pela livre atuação das operadoras - que se apresentavam numa miríade de formatos jurídicos institucionais -, por uma autorregulação débil, e por um crescente descontentamento dos consumidores com os produtos comercializados.

Ademais, a SUSEP era responsável apenas pela regulação do segmento das empresas Seguradoras, que comercializavam a modalidade de seguro-saúde. As empresas que comercializavam planos de saúde não queriam se submeter à fiscalização da SUSEP, alegando que "operar sob a modalidade de seguro-saúde [...] resultaria na monopolização do setor e redução do escopo de produtos ofertados". 3

Em verdade, a submissão das operadoras de planos de saúde à SUSEP representaria um controle mais intenso sobre os preços das mensalidades praticados pelas operadoras, "que muitas vezes não seguiam as regras de congelamento de preços formuladas nos planos econômicos do governo federal"3 além de resultar na incidência do imposto sobre operações financeiras (IOF).

Nesse panorama, os consumidores de planos e seguros privados de saúde eram atingidos por práticas abusivas configuradas principalmente pela negativa de cobertura de casos de doenças preexistentes, crônicas, congênitas e infecciosas; limitação de dias de internação em leitos de unidade de terapia intensiva (UTI); aumento abusivo no valor das mensalidades, entre outros.

A alternativa para a solução desses conflitos, ante a ausência de uma regulamentação sólida, era a busca pelo Poder Judiciário, que utilizava como fundamento de suas decisões, o Código de Defesa do Consumidor ( Lei nº 8.078, de 1991). 
Esse panorama de insatisfação generalizado culminou com a publicação da Lei $\mathrm{n}^{\circ} 9.656 \mathrm{em}$ 1998, fruto de uma "coalizão de interesses em torno da necessidade da regulamentação do segmento de planos de saúde".5-

A referida lei representou um marco na regulamentação da saúde suplementar no Brasil, ao dispor sobre planos e seguros privados de assistência à saúde. Antes dela não havia qualquer padrão no funcionamento dessa atividade, sendo a Superintendência de Seguros Privados (SUSEP) o órgão responsável pelo controle e fiscalização apenas do seguro saúde e das seguradoras. ${ }^{6}$

Assim, apesar das inúmeras alterações, a Lei no 9.656/98 representou um marco importante na saúde suplementar pois até então a temática era regulamentada por legislação muito antiga, e que não mais atendia aos problemas.

Completando o histórico da regulação da saúde suplementar no Brasil, apresenta-se, no bojo do Plano de Reforma do Aparelho Estatal, a criação da Agência Nacional de Saúde Suplementar ANS, através da Lei nº 9.961, de 2000.

A ANS apresenta-se como órgão de regulação, normatização, controle e fiscalização das atividades que garantem a assistência suplementar à saúde. Esse novo desenho institucional "encerrou um ciclo estrutural de abordagem do marco regulatório, remetendo ao Ministério da Saúde a responsabilidade pela regulação do setor [...]".3

Com relação à criação da Agência Nacional de Saúde Suplementar - ANS, o cenário situacional era representado por crises e escândalos, além das práticas abusivas protagonizadas pelo setor de saúde suplementar.

Constituíam práticas abusivas a negativa de acesso aos planos de saúde aos portadores de doenças psiquiátricas, doenças crônicas, doenças infecciosas, pois esses indivíduos iriam onerar o plano de saúde. Outra prática comum era a limitação no uso de determinados procedimentos como internação em UTI; sessões de fisioterapia, etc. ${ }^{5}$

A ANS foi criada como autarquia sob regime especial, vinculada ao Ministério da Saúde, com prazo de duração indeterminado e atuação em todo o território nacional. $\mathrm{O}$ fato de ser autarquia sob regime especial lhe confere uma série de prerrogativas, disposta em lei, que a torna mais independente, especialmente nos seguintes pontos: (i) estabilidade dos dirigentes; (ii) maior discricionariedade na sua atuação, (iii) independência financeira e (iv) autonomia decisória.

Desde sua criação, a ANS já promoveu a edição de inúmeras resoluções - Resoluções de Diretoria Colegiada, Resoluções Normativas e Resoluções Operacionais - com o fito de normatizar 
e fiscalizar as atividades de assistência suplementar à saúde, concentrando o ciclo regulatório da saúde suplementar na atualidade. Todavia, essa profusão de regulamentação não tem obstacularizado a profusão de ações judiciais na área da saúde suplementar.

\section{As demandas judiciais em saúde: o caso da Saúde Suplementar}

A explosão de demandas judiciais sobre o tema da saúde tem origem não apenas no setor público, mas também no de saúde suplementar, e apesar da existência de todo o marco regulatório, este ainda não se mostrou suficiente para reduzir o número de demandas judiciais.

Ao contrário, a preocupação do Poder Judiciário com o tema é de tal relevância, que em 12 de julho de 2011, o Conselho Nacional de Justiça - órgão responsável pelo controle da atuação do Poder Judiciário - editou a Recomendação $n^{\circ} 36$, em que sugere aos Tribunais de Justiça dos Estados e Tribunais Regionais Federais a adoção de medidas que visem à solução de demandas envolvendo a saúde suplementar.

O ponto nodal do conflito se dá principalmente porque há um descompasso entre os serviços que são ofertados no momento de se propagandear os planos e seguros de saúde, e a prestação efetiva do serviço. As operadoras de planos de saúde veiculam a mensagem de que seus produtos são modernos, resolutivos, e que o acesso aos serviços médicos e de diagnóstico de última geração são fáceis, incluindo a possibilidade de remoção aérea quando de uma necessidade. ${ }^{7}$

A busca por uma vida saudável, livre de limitações e sofrimento causado pelas doenças, hoje se apresenta como uma realidade possível de ser alcançada em virtude do avanço científico e tecnológico em matéria de saúde. Males antes incontroláveis hoje podem ser minimizados e até mesmo evitados em razão de inúmeros procedimentos disponíveis no mercado e propagandeado pelas operadoras de plano de saúde.

É esse o imaginário que leva o cidadão a firmar um plano privado de assistência à saúde, confiante de que terá acesso - a pelo menos - parcela desse avanço tecnológico das ciências médicas. Assim, quando frustrados no acesso a esses serviços, se socorrem ao Poder Judiciário na tentativa de ter reconhecido seus direitos de pessoa humana, digna, na garantia de sua saúde. ${ }^{7}$

Nesse sentido, como dito, se o direito à saúde é reconhecido na Constituição Federal como um direito fundamental e social, e se a atuação de empresas privadas no setor se dá apenas de forma suplementar, esses entes privados devem ter suas atividades pautadas dentro da lógica de entendimento constitucional do direito à saúde. Questões econômicas, contratuais, de concorrência e até aquelas envolvendo as de direito do consumidor devem ser subordinadas ao direito constitucional da saúde, pois a regulação deve ter como norte os fins da política social e os direitos 
a ela associados. ${ }^{8}$

O legislador constituinte quando inseriu o capítulo da saúde na Carta Magna de 1988, não criou regimes de tratamento diferenciados, por exemplo, um regime público, regido pela lógica do direito à saúde e um regime privado da saúde suplementar, guiado pela lógica do direito econômico. Ao revés, a saúde suplementar está inserida na Carta Magna na seção da saúde, no capítulo da seguridade social e no título da ordem social, da mesma forma que a saúde pública. ${ }^{9}$

Ou seja, se o legislador constituinte não inseriu o tema da saúde suplementar no título relacionado a ordem financeira e econômica é porque reconhece que essa temática deve ser tratada sob a mesma lógica constitucional do direito à saúde.

Nesse sentido se espera que o tratamento dado pelo Poder Judiciário nas demandas que envolvem a saúde suplementar observe a lógica dos direitos sociais. Os serviços de saúde, sejam públicos ou privados, devem obedecer aos princípios e diretrizes constitucionais que informam o direito à saúde.

Se as operadoras de planos de saúde criam obstáculos - por razões contratuais ou econômicas - aos seus usuários no acesso à assistência a saúde contratualizada, o direito à saúde também está sendo ofendido.

A atuação do Poder Judiciário brasileiro na solução de demandas sociais, em especial na área da saúde - pública e suplementar -, vem sendo objeto de estudo de inúmeros trabalhos científicos. ${ }^{10}$, 11, 12, 7, 9, 13 “A este protagonismo do Poder Judiciário enquanto espaço representacional no âmbito das relações sociais e políticas, os cientistas sociais costumam descrever como fenômeno da judicialização". ${ }^{13}$

O aumento da litigiosidade em matérias sociais concedeu lugar de destaque aos tribunais. A expansão desse poder judicial se dá sobremaneira pelo fenômeno da constitucionalização e normatização dos direitos, no período pós-autoritário dos anos de 1970 e 1980; na edição de constituições democráticas que vinham reforçar as instituições garantidoras do Estado Democrático de Direito, além do surgimento de discursos acadêmicos e jurídicos que vislumbram o papel importante do protagonismo judicial na defesa da nova ordem democrática. ${ }^{13}$

De igual modo, políticas que tinham como objetivo ampliar o acesso à justiça, em especial para cidadãos mais vulneráveis, foram implementadas pelo Estado brasileiro nesse processo de ampliação da democracia e reconhecimento de direitos sociais. Tem-se como exemplo a criação dos Juizados de Pequenas Causas, na década de 1980, transformados nos anos de 1990 em Juizados Especiais. 
Esse fortalecimento do papel de cidadania e a possibilidade de acesso à justiça foram reforçados ainda pela edição do Código de Defesa do Consumidor (Lei nº 8078 de 1990) e pela criação de órgãos ligados ao Sistema Nacional de Proteção ao Consumidor, fruto da consolidação da legislação consumeirista.

No campo da saúde suplementar, a problemática foi pauta da agenda governamental, e ante a ausência de política que dirimisse concretamente a litigiosidade entre as operadas e os usuários, o Poder Judiciário tem sido visto como bastião da defesa dos direitos do cidadão. De outro lado, o protagonismo de alguns órgãos do Poder Judiciário na solução de querelas tem reforçado esse papel.

O Poder Judiciário surge então como espaço legítimo e democrático de resolução de querelas interindividuais e coletivas, originadas dessas relações assimétricas presentes nas sociedades modernas.

Diante desse panorama, o fenômeno da judicialização deve ser entendido como um processo de transformação das normas e principalmente, da forma de atuação dos membros do Poder Judiciário na solução de questões sociais. É a atuação judicial com observância aos princípios da justiça social e da dignidade da pessoa humana, em detrimento a aplicação purista de princípios econômicos. No âmbito da saúde, essa atuação mais protagonista do Poder Judiciário tem garantido aos usuários de planos privados de assistência à saúde importantes conquistas e manutenção de diretos constitucionais duramente conquistados.

Essa mudança de paradigma, importante ressaltar, é fruto também da promulgação da Carta Magna de 1988, que marca a transição do sistema jurídico brasileiro, eminentemente positivista, para um sistema voltado à garantia de princípios da justiça social e da dignidade da pessoa humana.

Todos esses fatores contribuíram para a formação de um cidadão mais politizado e autônomo, que diante da ausência e/ou a fragilidade dos outros poderes - originariamente competentes - na solução de determinadas questões, passaram a demandar do Poder Judiciário essas respostas. Por outro lado, o Poder Judiciário não pode se imiscuir de seu papel de responder as demandas judiciais.

Nesse contexto é que se mostra a importância de investigar o posicionamento do Poder Judiciário nas questões de saúde suplementar.

\section{METODOLOGIA}

A pesquisa se concentrou na análise de decisões judiciais de $2^{\mathrm{a}}$ instância $^{(1)}$, proferidas pelo Tribunal de Justiça do Distrito Federal e Territórios, e coletadas na URL < www.tjdft.jus.br>, no período de 25 a 28 de abril de 2012. 
$\mathrm{Na}$ área de consulta aos despachos e decisões, foi selecionada como "espécie" a ser pesquisada apenas a apelação, e como "órgão julgador", a Turma Cível do respectivo tribunal. Os descritores utilizados na pesquisa na área de "busca livre” foram: a) plano e saúde; b) seguro e saúde e c) saúde e suplementar.

No total, a pesquisa analisou 16 acórdãos que versavam sobre saúde suplementar, publicados nos anos de 2009 (1 acórdão), 2010 (2 acórdãos) e 2011 (13 acórdãos).

Os resultados da pesquisa foram organizados em uma planilha geral, e depois agrupados de acordo com o requisito analisado, a saber: a) identificação das partes; b) objeto da discussão judicial; c) resultado do provimento jurisdicional de $2^{\mathrm{a}}$ instância e d) fundamentação jurídica da decisão.

\section{RESULTADOS}

\section{a) identificação das partes}

Dos acórdãos analisados, observou-se o predomínio do recurso de apelação ajuizado pelas operadoras de plano privado de assistência à saúde, num total de 87,5\% (gráfico 1).

Gráfico 1: Distribuição de processos no TJDFT por autoria da apelação.

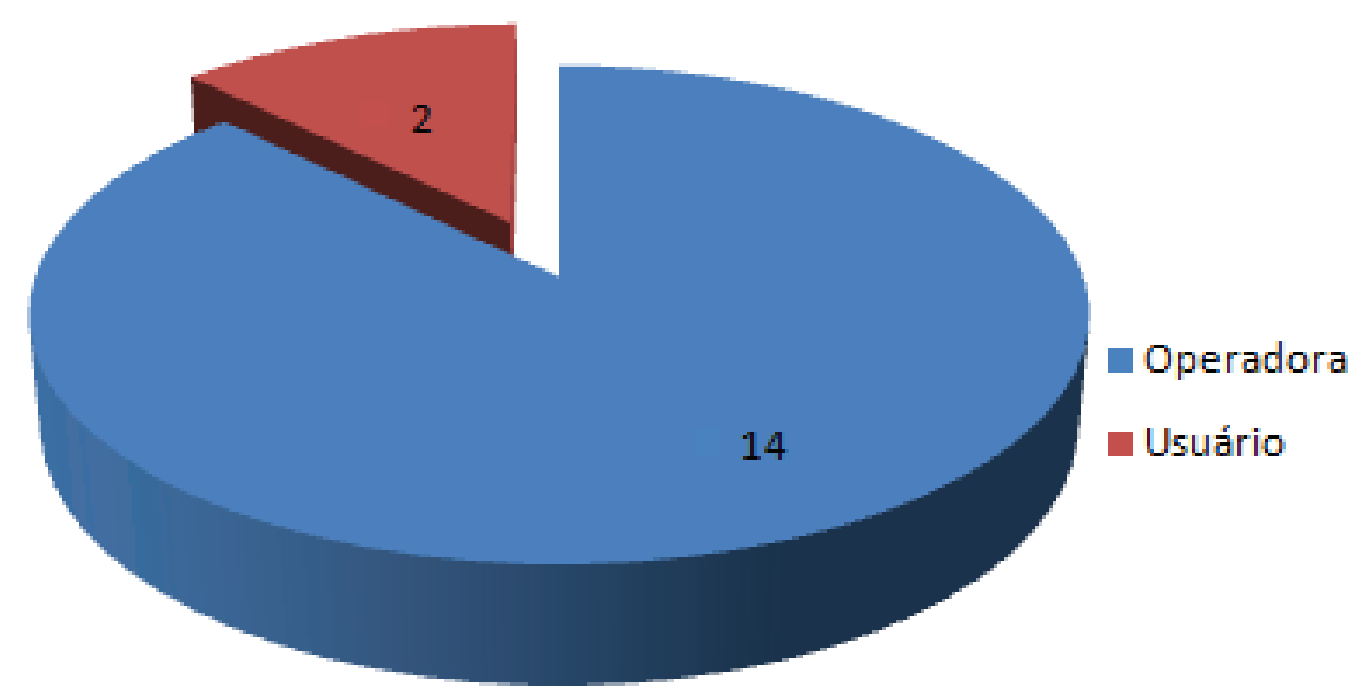

Fonte: Elaborado pela autora com base nos dados levantados na pesquisa.

Desse universo, os respectivos apelados eram usuários de planos privados e mantinham relação contratual com as respectivas operadoras. As operadoras apelantes representavam os seguintes segmentos: seguradora (2), medicina de grupo (1), autogestão (1) e cooperativa médica (3) (quadro $1)$. 
Quadro 1: Distribuição dos recursos de apelação por segmento e Operadora de Plano de Saúde (OPS)

\begin{tabular}{|c|c|c|}
\hline SEGMENTOS & $\begin{array}{l}\text { IDENTIFICAÇÃO DA OPERADORA DE PLANO DE } \\
\text { SAÚDE }\end{array}$ & $\begin{array}{l}\text { QUANTIDADE DE } \\
\text { APELAÇÕES }\end{array}$ \\
\hline \multirow{2}{*}{ Seguradoras de Saúde } & Sul América Seguro Saúde LTDA & 5 \\
\hline & Bradesco Saúde S/A & 1 \\
\hline Medicina de grupo & Golden Cross Assistência Internacional de Saúde LTDA & 3 \\
\hline Autogestão & $\begin{array}{l}\text { Caixa de Assistência dos Funcionários do Banco do Brasil } \\
\text { (CASSI). }\end{array}$ & 3 \\
\hline \multirow{3}{*}{ Cooperativas médicas } & $\begin{array}{l}\text { UNIMED RIO Cooperativa de Trabalho Médico do Rio de } \\
\text { Janeiro LTDA }\end{array}$ & \multirow{2}{*}{1} \\
\hline & $\begin{array}{l}\text { UNIMED Federação Interfederativa das Cooperativas } \\
\text { Médicas do Centro-Oeste e Tocantins }\end{array}$ & \\
\hline & UNIMED Confederação Centro Oeste e Tocantins & 1 \\
\hline \multicolumn{2}{|r|}{ TOTAL GERAL } & 14 \\
\hline
\end{tabular}

Fonte: Elaborado pela autora com base nos dados levantados na pesquisa.

\section{b) objeto da discussão judicial}

Dos acórdãos analisados foram observados três temas objeto de discussão judicial: cobertura (12), reintegração do usuário ao plano de saúde (2) e reajuste de mensalidade (1). Houve um caso que não tinha informação sobre o objeto de discussão por se tratar apenas de homologação de acordo, não contendo a síntese dos argumentos.

\section{c) resultado do provimento jurisdicional}

Do resultado do provimento jurisdicional de $2^{\mathrm{a}}$ instância foi realizada uma classificação a partir da procedência ou improcedência do julgamento tendo como referência o pleito do usuário/ beneficiário do plano de saúde (gráfico 2).

Gráfico 2: Distribuição de processos no TJDFT por resultado de segunda instância.

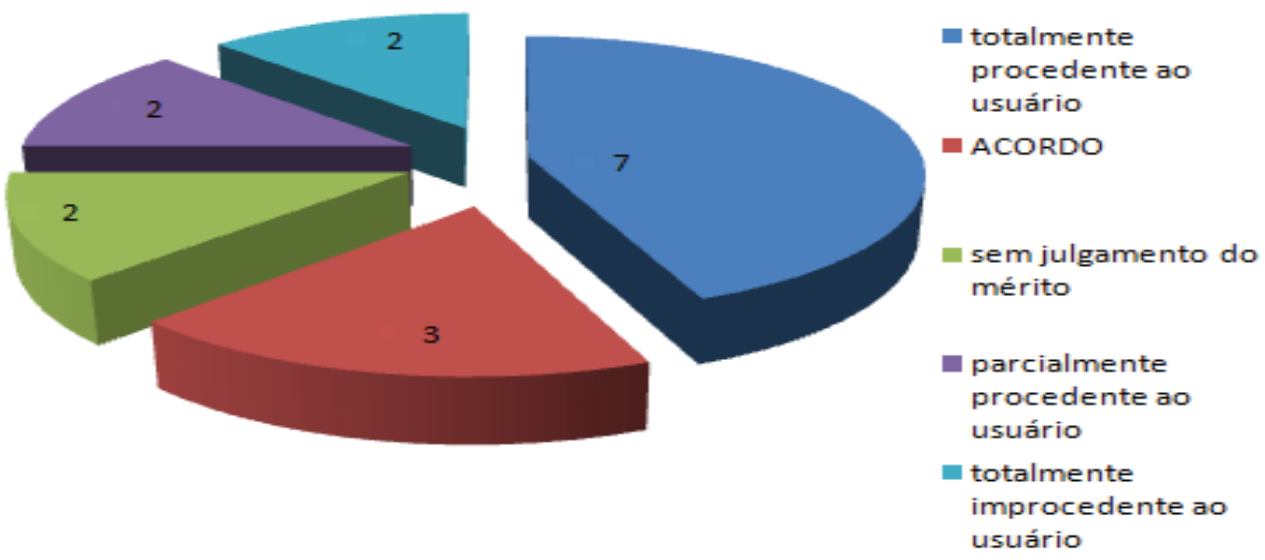

Fonte: Elaborado pela autora com base nos dados levantados na pesquisa. 
Os acórdãos procedentes ao pleito do usuário correspondem a 56,25\% da amostra, sendo $43,75 \%$ totalmente procedentes ao usuário, e 12,5\% parcialmente procedentes. Observou-se ainda 12,5\% de acórdãos com resultado de total improcedência ao pleito do beneficiário. Em ambos os casos, tratava-se de discussão sobre a reintegração de beneficiário ao plano de saúde. Os casos observados de processos sem julgamento do mérito decorriam de falhas processuais técnicas que impediam o regular seguimento do feito. Por fim, os acordos judiciais firmados entre usuário e a operadora de plano de saúde representaram 18,75\% dos pleitos. Em todos os casos, a OPS que celebrou o acordo foi a Sul América Seguro Saúde S/A.

\section{d) fundamentação jurídica da decisão}

Dos processos analisados foi possível identificar a fundamentação jurídica utilizada pelo TJDFT na solução de lides de saúde suplementar. Para tanto foi utilizada a seguinte classificação: a) fundamentação com base no Código de Defesa do Consumidor; b) fundamentação com base na Lei 9.656/98; c) Regulamentação da Agência Nacional de Saúde Suplementar e d) outros.

Na categoria outros se incluiu a referência ao Código de Processo Civil, Código Civil, Regimento Interno do TJDFT, e demais legislações não especificamente relacionada com o tema da saúde suplementar.

Gráfico 3: Distribuição de processos no TJDFT por fundamentação jurídica

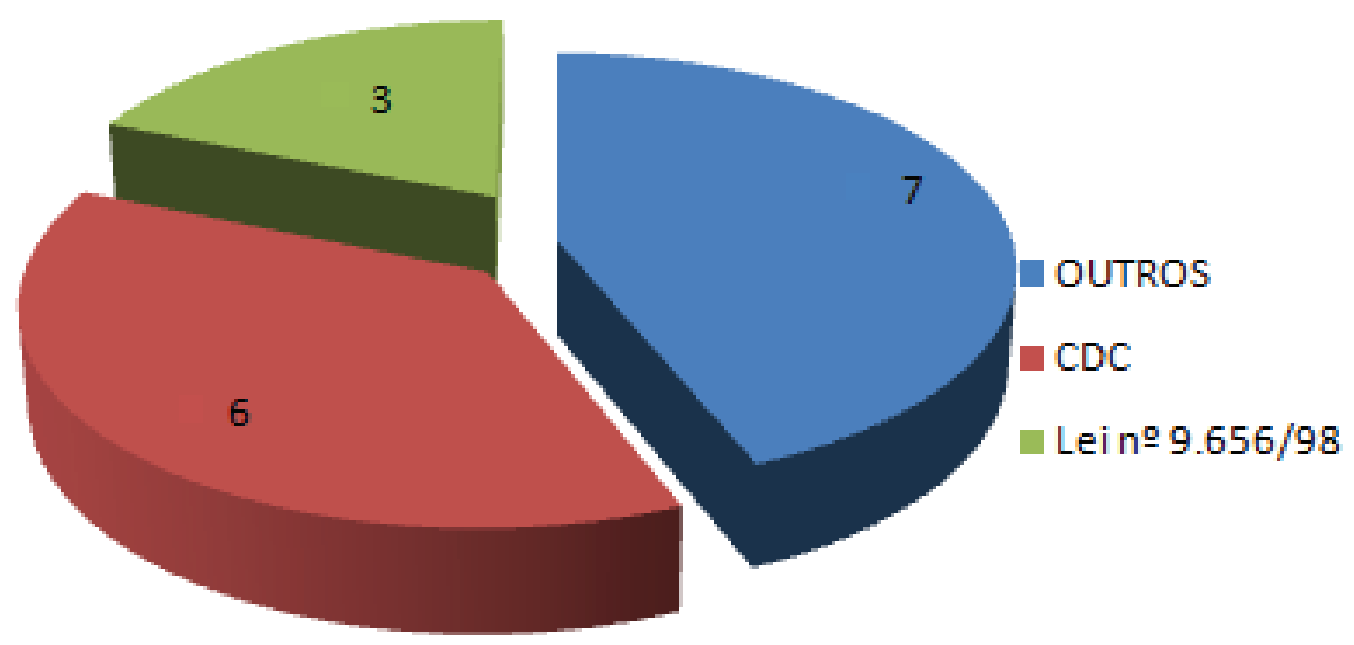

Fonte: Elaborado pela autora com base nos dados levantados na pesquisa

Observou-se que das decisões de $2^{\mathrm{a}}$ instância se fundamentou em normativas que direta - Lei $\mathrm{n}^{\mathrm{o}}$ 9656/98 (18,75\%) - e indiretamente - CDC (37,5\%) - estão relacionados com a saúde suplementar. Não houve referência as normas emitidas pela ANS. 


\section{DISCUSSÃO}

A pesquisa demonstrou a ausência de alguns segmentos específicos de OPS como autores de recursos judiciais, a saber: odontologia de grupo, cooperativas odontológica, filantrópicas e administradoras.

Uma provável causa para a baixa presença desses segmentos, é que essas modalidades de OPS não operam, comparativamente, com o mesmo número de vidas dos segmentos presentes na pesquisa. Dados da ANS demonstram que as OPS nas modalidades de empresas de autogestão, cooperativa médica, medicina de grupo e seguradoras de saúde compreendem $81 \%$ do mercado de grande porte, ou seja, aqueles que operam com mais de 100.000 vidas. $^{14}$

O índice de recursos de apelação ajuizados pelos usuários também foi baixo (12,5\%), e pode ser justificado pelo fato do primeiro grupo (segmentos das OPS) possuir grande capacidade econômica e uma estrutura jurídica forte, o que permite mais facilmente recorrer das decisões judiciais que são contrárias aos seus interesses.

O resultado também pode indicar que os provimentos judiciais de $1^{\mathrm{a}}$ instância têm se apresentado favoráveis ao pleito dos usuários dos planos de saúde, e por isso o interesse processual das operadoras em ver as decisões de $1^{\circ}$ grau reformadas é maior, justificando assim o alto índice de recursos ajuizados por esse segmento.

Nesse sentido, estudos mais detalhados devem ser produzidos com o objetivo de melhor desvendar essas nuances.

A discussão sobre a cobertura dos planos de saúde foi o tema mais identificado nos acórdãos analisados. Segundo a ANS, entende-se por cobertura assistencial, "o conjunto de procedimentos a que o consumidor tem direito, previsto na legislação de saúde suplementar e no contrato firmado com a operadora". ${ }^{15}$

A cobertura, portanto depende de uma série de fatores tais como: a) época que contrato de plano de saúde foi firmado, admitindo-se a coexistência de planos distintos que tem relação direta com a incidência da cobertura - plano antigo (contratados antes da Lei $n^{\circ}$ 9.656/98), plano novo (planos contratados a partir de 2 de janeiro de 1999 e comercializados conforme a lei $\mathrm{n}^{\circ}$ 9.656/98) e plano adaptado (são aqueles contratados antes da Lei ${ }^{\circ}$ 9.656/98, mas que posteriormente foram a ela adaptados); b) tipo de plano contratado - plano individual/familiar ou coletivo.

Nesse caso, as implicações do tipo de plano com a cobertura, estão mais relacionadas a questão de cumprimento de carências - menores ou inexistentes em planos coletivos - e preexistência de doenças - que nos planos individuais exige um cumprimento maior de carência para seu atendimento ou pagamento de um "agravo", diferente dos planos coletivos que não fazem qualquer restrição; c) cobertura assistencial obrigatória, a depender da segmentação do plano contratado: 
plano referência; ambulatorial, hospitalar e odontológico, combinados ou não; e d) vigência do contrato.

Ressalte-se que da pesquisa empreendida não foi possível obter informações sobre os tipos de contrato que os beneficiários possuíam, sendo impossível relacionar os pleitos - principalmente aqueles relacionados com a cobertura - com o tipo de plano.

A Lei $n^{\circ}$ 9656/98, em seu art. 12, além de dispor detalhadamente sobre o tipo de cobertura mínima específica de cada segmento de plano privado de assistência à saúde, também fixa prazo máximo de carência para alguns procedimentos específicos: a) 300 dias para partos a termo; b) 180 dias para os demais casos e c) 24 horas para coberturas em casos de urgências e emergências.

A ANS vem de forma reiterada, regulamentando o tema da cobertura assistencial, atualizando o rol de procedimentos e eventos em saúde, que constitui referência básica para cobertura mínima obrigatória a ser observada pelas operadoras de planos de saúde. Esse rol de cobertura mínima é aplicável aos contratos novos e aos contratos adaptados.

Assim, existe ampla legislação - legal e infralegal - a disciplinar o tema de cobertura de procedimentos e que deve ser observado pelos operadores do direito quando discussão judicial sobre o tema for realizada.

Outro tema presente foi o da reintegração de usuário ao plano de saúde e que está diretamente relacionado à manutenção da condição de beneficiário de plano de saúde oferecido pelo empregador em decorrência de vínculo empregatício, para ex-empregados e aposentados.

A discussão é pautada nos artigos 30 e 31 da Lei n ${ }^{\circ}$ 9.656/98 que dispõe sobre a possibilidade de funcionários que aderem ao plano de saúde em decorrência do vínculo empregatício, manterem-se como beneficiários do plano de saúde, no caso de rescisão ou exoneração do contrato de trabalho sem justa causa, e desde que assuma o pagamento integral da mensalidade.

Ao funcionário que se aposentar é garantido o mesmo direito, desde que tenha contribuído por pelo menos dez anos, e em decorrência de vínculo empregatício.

A ANS também regulamentou a questão através da Resolução Normativa $n^{\circ} 279$, expedida em 24 de novembro de 2011.

A Resolução da ANS estabelece que o funcionário que contribuiu para o plano e foi demitido sem justa causa pode permanecer no mesmo por período equivalente a $1 / 3$ do tempo de contribuição, respeitados limites mínimos de 6 (seis) meses e máximo de 2 (dois) anos. 
No caso dos aposentados que contribuíram por mais de 10 (dez) anos, podem permanecer no plano pelo tempo que decidirem. E quando o período de contribuição houver sido inferior aos 10 (dez) anos, o empregado aposentado tem o direito de se manter no plano à razão 1 (um) ano de permanência no plano após a aposentadoria para cada ano de contribuição. A regulamentação atinge os portadores de contratos novos ou adaptados.

Por fim, a questão do reajuste de mensalidade, que só pode ser realizado com autorização expressa da ANS no caso de planos contratados por pessoa física - planos individuais ou familiares - ou por empresas de autogestão financiadas exclusivamente com os recursos dos beneficiários. Essa restrição se aplica aos planos novos e adaptados.

O percentual de reajuste máximo autorizado pela ANS depende da análise da situação individual de cada operadora, pois é fundamentado em cálculos que incluem o número de beneficiários e outras informações sobre a situação específica da operadora.

Após a autorização de reajuste pela ANS, a operadora deve informar ao seu beneficiário, por ocasião do envio do boleto de pagamento, o percentual autorizado, o número do ofício que autorizou o reajuste e o nome e código do plano e número do registro do plano, quando existente.

No caso de reajuste de mensalidade de planos proveniente de contratos coletivos, o reajuste deve ser informado a ANS.

Importante registrar que a atuação da ANS nesses temas vem crescendo, pari passu a consolidação do processo de regulamentação da saúde suplementar. Nesse sentido, importante que em sede de discussão judicial sobre esses importantes temas, seja sempre citada a legislação que envolve o tema, seja para fortalecê-la, seja para exigir ajustes.

Com relação a fundamentação jurídica utilizada nas decisões judiciais, a grande surpresa foi a total ausência de referência nos julgados de $2^{\mathrm{a}}$ instância de qualquer normativa emitida pela ANS. Uma vez que esse é o órgão de regulação, normatização, controle e fiscalização das atividades que garantem a saúde suplementar, natural seria a citação de suas normativas na resolução de contendas judiciais.

Ademais, a Recomendação $n^{\circ}$ 36/2011 expedida pelo Conselho Nacional de Justiça dispõe sobre a formação e o aperfeiçoamento do magistrado através da realização de estudos e seminários sobre o tema, congregando também membros do Ministério Público e das operadoras de planos de saúde.

Formalmente os julgadores não podem alegar o desconhecimento da regulamentação expedida pela ANS, não obstante, a falta de citação das mesmas nos julgados pode levar a interpretação de 
que em verdade existe esse desconhecimento.

O grande número de pronunciamentos que utilizaram outras fundamentações $(43,75 \%)$ se justifica em virtude dos acordos celebrados que para sua homologação se utilizam de preceitos do Código de Processo Civil - CPC, bem como do número de processos que foram encerrados sem julgamento do mérito por questões de técnica processual. Nesses casos, a fundamentação também se faz tendo como base o CPC e/ou o Regimento Interno do TJDFT.

\section{CONSIDERAÇÕES FINAIS}

A realidade observada demonstra que as operadoras estão se imiscuindo da obrigação de prestar os serviços dentro dos parâmetros da legislação que regula essa atividade. Essa afirmação se confirma pela quantidade de decisões proferidas, e que foram totalmente procedentes ao beneficiário do plano de saúde. $\mathrm{O}$ dado do número de operadoras apelantes também reforça esse entendimento.

Por outro lado, se observou que o Poder Judiciário tem se mostrado atento na defesa dos usuários, e na garantia dos seus direitos. As relações assimétricas entre operadoras de planos privados de assistência à saúde e beneficiário estão sendo constantemente combatidas, e a aplicação de princípios de justiça social e dignidade da pessoa humana estão sendo sobrepostos a princípios econômicos e financeiros.

Outra conclusão de grande relevância foi a total ausência de referências a regulamentação expedida pela ANS. Apesar de não ter sido objeto desse estudo verificar o grau de capilaridade da ANS, a omissão de referências à ANS quando dos julgados sinaliza para a necessidade dessa agência reguladora empreender novos esforços no sentido de se fazer conhecer.

A finalidade da ANS e a sua competência estão dispostas em lei federal - Lei $n^{\circ}$ 9.961/2000 -, que é de conhecimento obrigatório aos membros do Poder Judiciário, contudo, para se fazer conhecer é preciso ir além.

Inúmeros assuntos tratados no âmbito do Poder Judiciário são detalhadamente regulamentados pela ANS, muitas vezes com participação da sociedade civil, através das consultas públicas, e sequer são citados pelos magistrados quando das decisões sobre saúde suplementar. Nesse sentido defende-se que a ANS e o Poder Judiciário podem e devem trabalhar conjuntamente na defesa do beneficiário do plano de saúde.

\section{REFERÊNCIAS BIBLIOGRÁFICAS}

1. Brasil. Ministério da Saúde. Agência Nacional de Saúde Suplementar. Perfil do Setor: dados gerais. [Acesso em 26 fev 2015].Disponível em http://www.ans.gov.br/index.php/materiais-para- 
pesquisas/perfil-do-setor/dados-gerais

2. Bahia L. Mudanças e padrões das relações público-privado: seguros e planos de saúde no Brasil [tese]. Rio de Janeiro: Escola Nacional de Saúde Pública da Fundação Oswaldo Cruz; 1999.

3. Cechin J. A história e os desafios da saúde suplementar: 10 anos de regulação. São Paulo: Saraiva: Letras \& Lucros; 2008. 302p. p. 79, 81, 107 e 124.

4. Bahia L. Os planos de saúde empresariais no Brasil: notas para regulamentação governamental [Internet].[data desconhecida][acesso em 13 mar 2015] 16p. Disponível em http://www.ans.gov. br/portal/upload/forum_saude/objeto_regulacao/AA7.pdf

5. Bahia L, Scheffer M. Planos e seguros de saúde: o que todos devem saber sobre a assistência médica suplementar no Brasil. São Paulo: Editora UNESP; 2010. 156p. p. 30

6. Melo PHF. O processo de regulação da assistência suplementar no Brasil. In: Pieratoni CR, Vianna CMM (Org.). Gestão de sistemas de saúde. Rio de Janeiro: UERJ, Instituto de Medicina Social; 2003. p. 355-383.

7. Alves DC, Bahia L, Barroso AF. O papel da justiça nos planos e seguros de saúde no Brasil. Cadernos de Saúde Pública [Internet]. 2009 [acesso em 13 mar 2015]; 25(2): p. 279-290. Disponível em http://www.scielo.br/pdf/csp/v25n2/06.pdf

8. Nogueira RP. As agências reguladoras da saúde e os direitos sociais. Texto para discussão $\mathrm{n}^{\circ}$ 599. [Internte]. 2002 [acesso em 20 mar 2012]. Disponível em http://www.ipea.gov.br/sites/000/2/ publicacoes/bpsociais/bps_05/ensaio1_Roberto.pdf Brasília:

9. Trettel DB. Planos de saúde na Justiça: o direito à saúde está sendo efetivado? Estudo do posicionamento dos Tribunais Superiores na análise dos conflitos entre usuários e operadoras de planos de saúde [dissertação]. São Paulo: Faculdade de Direito, Universidade de São Paulo; 2009.

10. Marques SB. Judicialização do direito à saúde. Revista de Direito Sanitário [Internet]. 2008 [Acesso em 20 mar 2014]; 9 (2): p. 65-72. Disponível em http://www.revistas.usp.br/rdisan/article/ viewFile/13117/14920

11. Delduque MC, Marques SB, Romero LC. A saúde precisa de juízes epidemiologistas. Saúde em Debate [Internet]. 2009 [Acesso em 20 mar 2014]; 33(81): p. 80-87. Disponível em http://docvirt.com/asp/acervo_cebes.asp?Bib=SAUDEDEBATE\&PASTA=V.33\%2C+N.81++ jan $\&$ pesq $=\& \mathrm{x}=74 \& \mathrm{y}=12$

12. Delduque MC. Controle judicial da política pública de vigilância sanitária: a proteção da saúde no Judiciário [tese]. São Paulo: Faculdade de Saúde Pública, Universidade de São Paulo; 2010. 
13. Souza MHSC, Bahia L, Vianna MLW, Scheffer M, Salazar A, Grou KB. A intervenção do Poder Judiciário no setor de saúde suplementar - tutelas antecipadas como instrumento de garantia da assistência à saúde no Brasil. Divulgação em Saúde para Debate [Internet]. 2007[Acesso em 20 mar 2015]; (37): p. 44-60. Disponível em http://abresbrasil.org.br/sites/default/files/poder_ judiciario_bahia.pdf

14. Brasil. Ministério da Saúde. Agência Nacional de Saúde Suplementar. Caderno de Informação de Saúde Suplementar: beneficiários, operadoras e planos. Rio de Janeiro: ANS; 2011.

15. Brasil. Ministério da Saúde. Agência Nacional de Saúde Suplementar. Cobertura assistencial: contratos, tipos de plano, coberturas obrigatórias, planos novos e adaptados. Rio de Janeiro: ANS; 2005. 29p. (Planos de saúde: conheça seus direitos) p. 6

Nota

(1) Para a ciência jurídica, instância é compreendida como o local onde o processo se encontra para ser julgado. Nesse sentido, a $2^{\mathrm{a}}$ instância já compreende o grau hierárquico superior em que o processo foi iniciado.

Artigo apresentado em 14-01-15

Artigo aprovado em 20-11-15 Artigo publicado no sistema em 22-12-15 